\title{
Dual usage of a stone basket: Stone capture and retropulsion prevention
}

Tadeusz Kroczak; Daniela Ghiculete; Robert Sowerby; Michael Ordon; Jason Y. Lee; Kenneth T. Pace; John R. D'A Honey

Department of Surgery, Division of Urology, University of Toronto, St. Michael's Hospital, Toronto, ON Canada

Cite as: Can Urol Assoc J 2018 May 28; Epub ahead of print. http://dx.doi.org/10.5489/cuaj.5021

Published online May 28, 2018

$* * *$

\section{Abstract}

Introduction: Stone migration during ureteroscopy (URS) for proximal ureteric calculi is a constant challenge. Several retropulsion prevention devices have been developed in order to optimize URS outcomes. Our technique involves capturing the stone within a four-wire Nitinol stone basket and then preforming laser lithotripsy to dust the stone while it is engaged in the basket. The dusted fragments wash out with the irrigation fluid and once small enough, the remaining stone is removed intact.

Methods: A retrospective chart review was preformed of all proximal URS procedures performed with semi-rigid URS for a solitary calculus (2000-2016). We compared our new technique introduced in 2010 to URS control procedures that did not use retropulsion prevention techniques or devices.

Results: One hundred and forty patients underwent URS for proximal ureteric calculi. Mean stone diameter was $9.3 \pm 3.4 \mathrm{~mm}$, with similar impaction rate between both groups ( $44.1 \%$ vs. $43.1 \%$ control; $\mathrm{p}=\mathrm{n} / \mathrm{s}$ ). The mean surgical procedure time was $53.3 \pm 17.9$ minutes for the new technique and $65.2 \pm 29.2$ minutes for the control group $(\mathrm{p}=0.005)$. Compared to the new technique, the control group had a higher rate of retropulsion ( $33.3 \%$ vs. $14.7 \%$; $\mathrm{p}=0.01$ ) and required flexible URS more often to exclude or remove residual fragments ( $24.1 \%$ vs. $59.1 \%$; $\mathrm{p}=0.001)$. Using the new technique, stone-free rates were higher ( $79.1 \%$ vs. $69.4 \% ; \mathrm{p}=\mathrm{n} / \mathrm{s})$ and there was a lower likelihood of leaving residual fragments both $<3 \mathrm{~mm}$ and $\geq 3 \mathrm{~mm}(\mathrm{p}=0.001)$.

Conclusions: Our novel technique results in shorter operative times, lower retropulsion rates, and decreases postoperative residual stone fragments. 


\section{Introduction}

Stone migration during ureteroscopy (URS) for proximal ureteric calculi is a constant challenge. Traditionally ureteric stones that fail conservative treatment, fail shockwave lithotripsy (SWL), or are too large to be extracted intact, require some form of intraureteric lithotripsy. Among the various modalities available, laser lithotripsy has emerged as the safest and most efficient. Most urologists approach ureteric calculi by using laser lithotripsy either to fragment or "dust” the stone. A basket is then used to extract small stone fragments. Occasionally fragments may migrate up to the kidney requiring prolonged operative times, increased cost and secondary procedures. Between 3 and 15\% of stones in the distal ureter ${ }^{1,2}$ and $28-48 \%$ of proximal stones ${ }^{3,4,5}$ undergo retrograde migration.

Several retropulsion prevention devices have been developed in order to optimize URS outcomes and to prevent proximal migration. These devices are either mechanical(wire-based or balloon-based) or gel based. They are typically placed above the stone to prevent retropulsion and improve removal of fragments with removal of the instrument. Wire-based devices may potentially injure the ureter and this may be a limiting factor in their adoption. ${ }^{6}$ These devices are typically expensive and not necessarily available to all urologists. Furthermore, there is limited data available on the effectiveness of these devices. Examples of these devices are shown in the table I.

Our technique involves capturing the stone within a four wire Nitinol stone basket [Cook Medical] and preforming laser lithotripsy $(0.4 \mathrm{~J}$ and $20 \mathrm{~Hz})$ to dust the stone while in the basket (See Image 1). The dusted fragments wash out with the irrigation fluid and once small enough; the remaining stone is removed intact within the basket. If the stone is too large or impacted then careful dusting of the stone until it may be trapped within the basket is performed.

\section{Methods}

A retrospective chart review was preformed of all proximal URS procedures preformed for a solitary calculus (2000-2016). Demographic data on all patients including age, gender, comorbidities and prior urologic history was collected. Stone characteristics such as stone size and composition were included. Indications for ureteroscopy ranged from failure of conservative management, failure of extracorporeal shock wave lithotripsy, or initial treatment for renal colic. Some patients had stents inserted prior due to symptomatic obstruction or infection. We excluded patients with either multiple ureteric or renal calculi, patients with congenital urologic anomalies, or ureteric stricture.

Operative variables collected included: operative time, laser fiber size and settings, number and size of Nitinol baskets, presence of stone impaction, use of flexible URS, intra-operative complications, use of ureteric access sheath, and retropulsion. We defined "retropulsion" as intra-operative migration of a ureteric stone or stone fragments to the kidney. This was confirmed with the use of flexible URS in addition to rigid URS. 
Stone free was defined as the absence of residual stone fragment $\leq 3 \mathrm{~mm}$ on KUB xray at the 1 to 2 week follow up along with stent removal. An ultrasound was also preformed at 1 to 3 months to confirm absence of stone and hydronephrosis.

We compared our new technique in consecutive patients when introduced in 2010 to URS control procedures that did not use retropulsion prevention techniques or devices prior to 2010. Chi squared analysis and ANOVA were used for statistical analysis.

\section{Results}

One hundred and forty patients (87 males \& 53 females) underwent semi-rigid URS for solitary proximal ureteric calculi. Abdominal hand pressure over the iliac vessels on the affected side was used to assist access to the upper ureter if required. ${ }^{7}$ Patient and clinical characteristics are presented in table II. Sixty eight patients were treated using the new anti-retropulsion technique and 72 patients were in the control group. Mean age in both groups was $56.1 \pm 16.4$ years with a mean BMI of $28.9 \pm 7.7\left(\mathrm{~kg} / \mathrm{m}^{2}\right)$. Mean stone diameter was $9.3 \pm 3.4 \mathrm{~mm}$ with similar impaction rate between both groups $(44.1 \% \mathrm{vs}$. $43.1 \%$ control), $\mathrm{p}=\mathrm{n} / \mathrm{s})$. The number of patients with stents placed preoperatively was similar with 20 (25.3\%) in the new technique group and 23 (31.9\%) in the control group $(\mathrm{p}=\mathrm{n} / \mathrm{s})$.

The mean surgical procedure time was $53.3 \mathrm{~min} \pm 17.9$ for the new technique and $65.2 \mathrm{~min} \pm 29.2$ for the control group $(\mathrm{p}=0.005)$. Surgical characteristics are presented in Table III. Compared to the new technique, the control group had a higher rate of retropulsion ( $33.3 \%$ vs. $14.7 \%, \mathrm{p}=0.01$ ) and required flexible URS more often to exclude or remove residual fragments ( $59.1 \%$ vs. $24.1 \%, p=0.001)$. When flexible ureteroscopy was used, there was no difference between the two groups with respect to use of ureteric access sheaths. Using the new technique stone free rates were higher $(79.1 \%$ vs. $69.4 \%$, $\mathrm{p}=\mathrm{n} / \mathrm{s}$ ) and there was a lower likelihood of leaving residual fragments both $<3 \mathrm{~mm}$ and $\geq 3 \mathrm{~mm}$ ( $\mathrm{p}=0.002$ ). Rate of ureteric injury (3 (4.4\%) new technique, 3 (4.2\%) control group) were all minor superficial ureteric mucosal injuries treated with ureteric stents. Ten patients required the use of an additional basket during the new procedure due to damage to the basket by the laser. This damage did not result in any further complication. No patients developed ureteral strictures. The incidence of urinary tract infection (3 (4.1\%) new technique, 3 (3.8\%) control group) was identical between both groups. The need for secondary procedures was similar between both techniques. Three patients (4.4\%) required a secondary procedure in the new technique with SWL and no patients required a secondary URS. This was in contrast to the control group where 3 patients required SWL and one patient required a repeat URS for residual fragments. 


\section{Discussion}

Our technique has been used at our institution for nearly two decades and has shortened operating times and the need for auxiliary procedures and equipment. The basket and wire are passed through the same working channel of the semi-rigid ureteroscope. This gives the operator the option to use a larger basket (up to 2.4Fr) which allows for easier basket manipulation while maintaining adequate irrigation flow. If the stone is irregular the basket may be rotated to facilitate placing the laser on the desired location on the stone. A larger laser fiber $(365 \mu \mathrm{m})$ is usually used to reduce movement of the laser fiber and to facilitate dusting efficiency. We typically begin with laser settings of $0.4 \mathrm{~J}$ and $20 \mathrm{~Hz}$ and titrate either energy or frequency according to the stone quality. The larger fiber size is also easier to manipulate. A disadvantage of our technique is that while using the laser with the stone engaged in the basket, there is a potential to disrupt a tine on the basket. Certainly this is a concern and it does occasionally happen. In the vast majority of cases the stone remains trapped within the basket with the remaining three tines. This does expose more of the stone that is accessible to fragment with the laser and rarely an additional basket required. Most retropulsion prevention devices still require the use of a basket and some form of lithotripsy. Our technique minimizes the need for additional instruments that can help reduce costs, even if the occasional additional basket is required.

While our technique is unique, there is a device available that is based on a similar concept. The Escape ${ }^{\circledR}$ nitinol stone retrieval basket (Boston Scientific, Natick, MA) does allow for simultaneous use of a basket and laser to treat stones. The device is a two-port adaptor that allows passage of a $1.9 \mathrm{~F}$, zero-tip, four-wire nitinol stone retrieval basket and $200 \mu \mathrm{m}$ laser fiber. The Escape ${ }^{\circledR}$ can be opened at two different levels-11 $\mathrm{mm}$ and $15 \mathrm{~mm}$ for stone retrieval, grasping, or disengaging stones. A small pilot study was preformed and published as an abstract by Kesler et al which included 23 patients with 14 patients having ureteric calculi and 9 patients with renal calculi. A stone free rate of $100 \%$ was reported for patients with ureteric calculi, however location within the ureter and retropulsion of stone fragments was not specified. ${ }^{8}$

The Stone Cone ${ }^{\mathrm{TM}}$ and PercSys Accordion ${ }^{\circledR}$ demonstrate greater clinical success for stones located in dilated proximal ureters than other devices currently available. The Stone Cone ${ }^{\mathrm{TM}}$ was first described in 2001 and has subsequently become one of the most studied anti-retropulsion devices. ${ }^{9-14}$ This device consists of an outer radio-opaque carrying sheath and a 3 part inner wire. The cone which is made from stainless steel covered with Nitinol and molded into a spiral form is contained within a carrying catheter which when advanced allows for deployment. Most of the published results with the Stone Cone $^{\mathrm{TM}}$ have been with pneumatic lithotripsy or electrohydraulic lithotripsy. Desai et al preformed 50 URS procedures with no stone migration or residual fragments postoperatively. ${ }^{12}$ No patients required auxiliary procedures, however twenty six of the fifty 
patients had distal or mid ureteric calculi which are less prone to retropulsion. Paradis et al identified patients with proximal and distal ureteric calculi and compared pneumatic and electrohydraulic lithotripsy with and without the Stone Cone ${ }^{\mathrm{TM}} .{ }^{13}$ None of the thirty patients who underwent URS with the Stone Cone ${ }^{\mathrm{TM}}$ required additional procedures for residual stone fragments. We have only used Holmium laser lithotripsy with our technique, however pneumatic lithotripsy could be successfully preformed. Finally, a group led by Eisner reported on the Stone Cone ${ }^{\mathrm{TM}}$ with laser lithotripsy. They reported a $1.5 \%$ retropulsion rate and two patients required additional procedures for fragments larger than $2 \mathrm{~mm}$. Twenty eight patients (21\%) required flexible URS in addition to semirigid URS. ${ }^{14}$ Stone size was not included in this retrospective review.

The PercSys Accordion ${ }^{\circledR}$ is advanced with fluoroscopy or endoscopic guidance beyond the stone and once deployed a multifold polyurethane film forms filling the ureter and thereby preventing retropulsion. The manufacturer claims that this device is advantageous since retropulsion is prevented regardless of laser energy or ureteral diameter. A randomized prospective trial of 23 patients with distal ureteric calculi found that the device caused significantly less retrograde migration during fragmentation with an impact lithotripter. ${ }^{15} \mathrm{Wu}$ et al conducted a retrospective review of 235 patients with ureteric calculi treated with and without the Accordion as well as laser lithotripsy. ${ }^{16}$ The device did not result in a significant reduction fluoroscopy time or operating time, but did produce a significantly higher stone free rate.

Few comparative clinical studies have been preformed between the various available retropulsion devices. Farhat et al preformed a prospective randomized trial with the Stone Cone and N-Trap. ${ }^{17}$ Both devices were compared to a control group, the Stone Cone was found to have a lower rate of stone migration and a statistically significant stone free rate when compared to the other two groups. Subsequent procedures were required in 3 (4.76\%) patients with the Stone Cone and 10 (16.94\%) with the N-Trap. This study used pneumatic lithotripsy for stone destruction.

\section{Conclusion}

Stone migration during ureteroscopy (URS) for proximal ureteric calculi is a constant challenge. While several retropulsion devices have been developed, our simple and novel technique results in shorter operative times, lower retropulsion rates and decreases postoperative residual stone fragments. 


\section{References}

1. Hendrik AJ, Strijbos WE, deKnijff DW, Kums JJ, Doesburg WH, Lemmens WA. Treatment for extended mid and distal ureteral stones: SWL or ureteroscopy? Results of a multi-center study. J Endo Eurol. 1999; 13(10): 727-733

2. Pardalidis NP, Kosmaoglou EV, Kapotis CG. Endoscopy vs. extracorporeal shockwave lithotripsy in treatment of distal ureteral stones: ten years experience. J Endourol. 1999; 13(3): 161-164.

3. Chow GK, Patterson DE, Blute ML, Segura JW. Ureteroscopy: effect of technology and technique on clinical practice. J Urol. 2003; 170(1): 111.

4. Knispel HH, Klan R, Heicappell R, Miller K. Pneumatic lithotripsy applied through deflected working channel of miniuretersope: results in 143 patients. J Endourol. 1998; 12(6): 513-515.

5. Robert M, Bennani A, Guiter J, Avérous M, Grasset D. Treatment of 150 ureteric calculi with the lithoclast. Eur Urol. 1994; 26(3): 212-215.

6. Dretler SP. Preventing stone migration during ureteroscopy: The Stone Cone Rules. Contemporary Urology. October 6, 2006.

7. Dagnone AJ, Blew BD, Pace KT, Honey RJ. Semirigid ureteroscopy of the proximal ureter can be aided by external lower-abdominal pressure. J Endourol. 2005 Apr;19(3):342-7.

8. Kesler SS, Pierre SA, Brison DI, Preminger GM, Munver R. Use of the Escape nitinol stone retrieval basket facilitates fragmentation and extraction of ureteral and renal calculi: a pilot study. J Endourol Soc. 2008;22(6):1213-7

9. Dretler SP. The stone cone: a new generation of basketry. J. Urol. 2001. 15931596.

10. Maislos SD. Efficacy of the StoneCone for treatment of proximal ureteral stones. J. Endourol. 2004. 18; 862-864.

11. Gonen M, Cenker A, Istanbulluoglu O, Ozkardes H. Efficacy of Dretler Stone Cone in the treatment of ureteral stones with pneumatic lithotripsy. Urol. Int. 2006. 76; 159-162.

12. Desai, MR, Patel SB, Desai MM, et al. The Dretler stone cone: a device to prevent ureteral stone migration: the initial clinical experience. J. Urol.2002; 167,1985-88.

13. Pardalidis NP, Papatsoris AG, and Kosmaoglou EV. Urol Res 2005; 33 61-61.

14. Eisner BH and Dretler SP. Use of the Stone Cone for prevention of calculus retropulsion during holium:YAG laser lithotripsy: case series and review of the literature. Urol. Int. 2009; 356-360.

15. Pagani CJ, El Akkad M, Bagley DH. Prevention of stone migration with the Accordion during endoscopic uretral lithotripsy.J. Endourol. 2012. 26;484-488. 
16. Wu JA, Ngo TC, Hagedorn JC, Macleod LC, Chung BI, Shinghal R. The accordion antiretropulsive device improves stone-free rates during ureteroscopic laser lithotripsy. J Endourol. 2013 Apr;27(4):438-41.

17. Farahat YA, Elbahnasy AE, Elashry OM. A randomized prospective controlled study for assessment of different ureteral occlusion devices in prevention of stone migration during pneumatic lithotripsy. Urology (2011), 77;30-35 


\section{Figures and Tables}

Fig. 1. Instrument setup. A four-wire Nitinol stone basket and laser fiber are passed through a single-channel, semi-rigid ureteroscope.
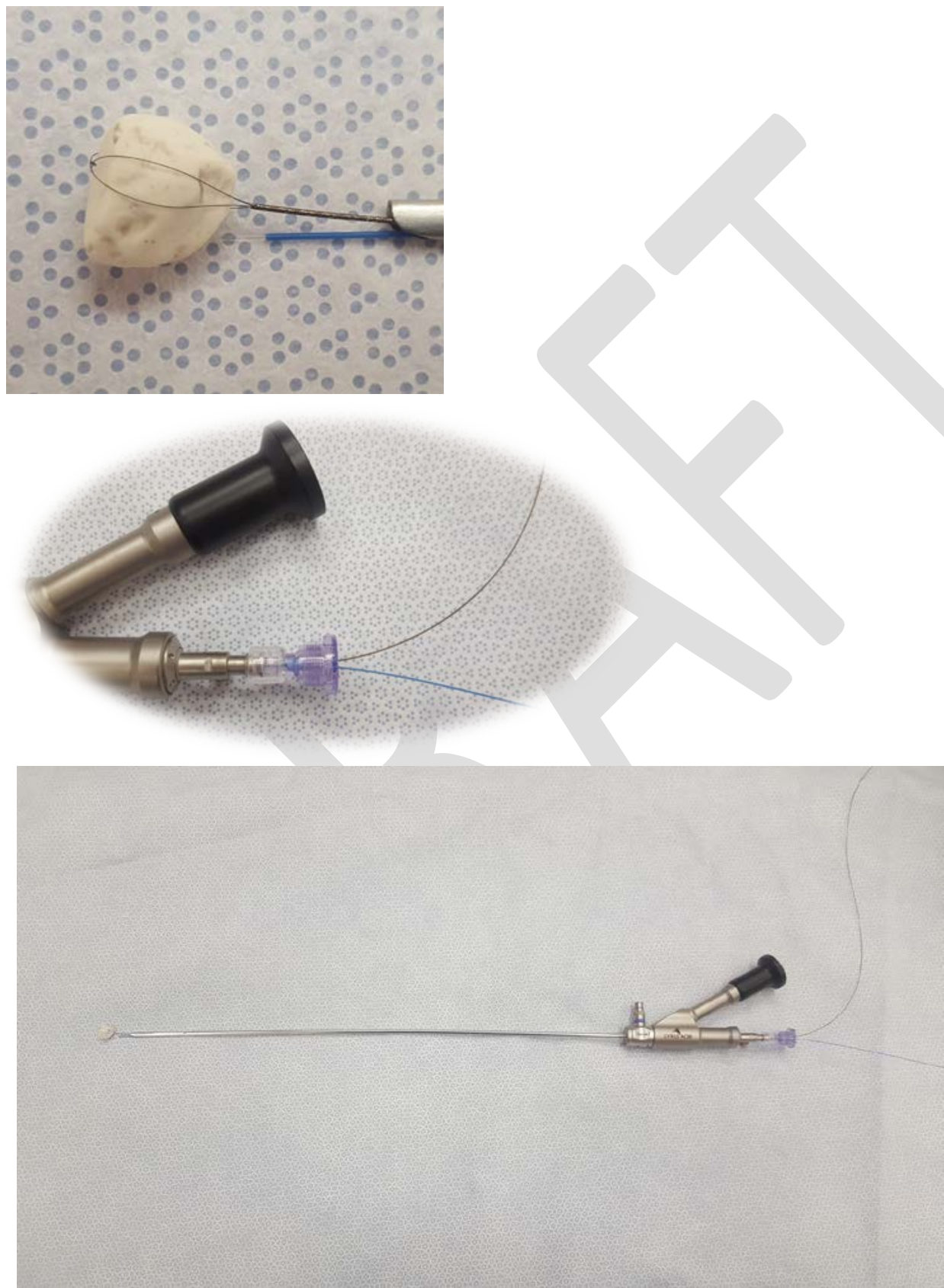


\begin{tabular}{|c|c|c|c|c|c|}
\hline Author & Year & Device/Technique & $\mathbf{n}$ & $\begin{array}{l}\text { SFR } \\
(\%)\end{array}$ & $\begin{array}{c}\text { Stone } \\
\text { migration (\%) }\end{array}$ \\
\hline Dretler et al $^{7}$ & 2000 & $\begin{array}{l}\text { Balloon catheter } \\
\left.\text { (Passport }^{\circledR}\right)\end{array}$ & 29 & 89.7 & 10.3 \\
\hline Mohseni et $\mathrm{al}^{8}$ & 2006 & $\begin{array}{c}\text { Gel-based } \\
\text { (Lidocaine jelly) }\end{array}$ & 16 & 93.7 & 12.4 \\
\hline${\text { Kesler et } \mathrm{al}^{9}}^{9}$ & 2008 & $\begin{array}{c}\text { Stone basket } \\
\left(\text { Escape }^{\circledR}\right)\end{array}$ & 23 & 87 & n.a. \\
\hline${\text { Eisner et } \mathrm{al}^{10}}^{10}$ & 2009 & $\begin{array}{l}\text { Guidewire (Stone } \\
\text { Cone }^{\circledR} \text { ) }\end{array}$ & 133 & 98.5 & 1.5 \\
\hline Rane et $\mathrm{al}^{11}$ & 2010 & $\begin{array}{c}\text { Thermosensitive } \\
\text { polymer } \\
\left(\text { BackStop }^{\circledR}\right)\end{array}$ & 34 & 87.8 & 8.8 \\
\hline Wang et $\mathrm{al}^{12}$ & 2011 & Guidewire (NTrap $\left.{ }^{(}\right)$ & 56 & 100 & 0.0 \\
\hline Sen et $\mathrm{al}^{13}$ & 2014 & $\begin{array}{c}\text { Guidewire (Stone } \\
\text { Cone }^{\circledR} \text { ) }\end{array}$ & 25 & 95.5 & 4.5 \\
\hline Sen et $\mathrm{al}^{13}$ & 2014 & $\begin{array}{l}\text { Guidewire } \\
\left(\text { PercSys }^{\circledR}\right)\end{array}$ & 25 & 91.3 & 8.7 \\
\hline Sen et $\mathrm{al}^{13}$ & 2014 & $\begin{array}{c}\text { Gel-based } \\
\text { (Lidocaine jelly) }\end{array}$ & 25 & 82.6 & 21.7 \\
\hline
\end{tabular}




\begin{tabular}{|l|c|c|c|}
\hline \multicolumn{4}{|l|}{ Table 2. Patient and clinical characteristics } \\
\hline & Control & New technique & p \\
\hline Age & $57.8 \pm 17.2$ & $53.9 \pm 15.9$ & $\mathrm{n} / \mathrm{s}$ \\
\hline BMI & $29.4 \pm 8.7$ & $28.5 \pm 7.4$ & $\mathrm{n} / \mathrm{s}$ \\
\hline $\begin{array}{l}\text { Stone diameter } \\
(\mathrm{mm})\end{array}$ & $9.3 \pm 3.8$ & $9.2 \pm 3.1$ & $\mathrm{n} / \mathrm{s}$ \\
\hline $\begin{array}{l}\text { Gender } \\
\text { Female }\end{array}$ & $26(36.1 \%)$ & $27(39.7 \%)$ & $\mathrm{n} / \mathrm{s}$ \\
Male & $46(63.9 \%)$ & $41(60.3 \%)$ & \\
\hline $\begin{array}{l}\text { Side } \\
\text { Left } \\
\text { Right }\end{array}$ & $34(47.2 \%)$ & $40(58.8 \%)$ & $\mathrm{n} / \mathrm{s}$ \\
\hline Impacted & $38(52.8 \%)$ & $28(41.2 \%)$ & $\mathrm{n} / \mathrm{s}$ \\
\hline Stent preoperative & $31(43.1 \%)$ & $30(44.1 \%)$ & $\mathrm{n} / \mathrm{s}$ \\
\hline BMI body (31.9\%) & $20(25.3 \%)$ &
\end{tabular}

BMI: body mass index.

\begin{tabular}{|l|c|c|c|}
\hline \multicolumn{4}{|l|}{ Table 3. Results of surgical outcomes } \\
\hline Retropulsion & Control & New technique & p \\
\hline $\begin{array}{l}\text { Rigid+flexible } \\
\text { URS }\end{array}$ & $36(59.3 \%)$ & $10(14.7 \%)$ & $\mathbf{0 . 0 1}$ \\
\hline Stone-free & $50(69.4 \%)$ & $19(24.1 \%)$ & $\mathbf{0 . 0 0 1}$ \\
\hline $\begin{array}{l}\text { Residual } \\
<3 \text { mm } \\
>3 \text { mm }\end{array}$ & $\begin{array}{c}5(79.1 \%) \\
\text { (15.5\%) }\end{array}$ & $\begin{array}{c}11(16.2 \%) \\
2(2.9 \%)\end{array}$ & $\mathbf{n} / \mathrm{s}$ \\
\hline $\begin{array}{l}\text { Ureteric injury } \\
\text { injury }\end{array}$ & $3(4.2 \%)$ & $3(4.4 \%)$ & $\mathrm{n} / \mathrm{s}$ \\
\hline UTI & $3(4.2 \%)$ & $3(4.4 \%)$ & $\mathrm{n} / \mathrm{s}$ \\
\hline $\begin{array}{l}\text { Sec. procedure } \\
\text { SWL }\end{array}$ & $3(4.2 \%)$ & $3(4.4 \%)$ & $\mathrm{n} / \mathrm{s}$ \\
URS & $1(1.4 \%)$ & 0 & \\
\hline
\end{tabular}

${ }^{*}$ Minor superficial ureteric mucosal. SWL: fail shockwave lithotripsy; URS: ureteroscopy; UTI: urinary tract infection. 